\section{DIARY}

BDA UCL Eastman Careers Day

Date: 8 February 2013

Venue: Hotel Russell, London

www.bda.org/events/1359-careersday-2013friday-8-february-

2013london.aspx

8th Young Dentist Conference

Date: 9 February 2013

Venue: Royal College of Physicians, London

Telephone: 02073991339

www.dentalprotection.org/ydc

On the Road to Better Aesthetics

Date (Venue): 9 February 2013

(Coventry Transport Museum);

15 February 2013

(The Sage, Gateshead);

16 February 2013 (London Zoo)

Telephone: 08458736299

Email: sales@conferenceshop.com

BDA Seminar -

Modern teeth whitening

Date: 1 March 2013

Venue: BDA, London

Email events@bda.org

Telephone: 02075634590

www.bda.org/seminars

Alpha Omega dental fraternity

Jerusalem Conference

Date: 7-11 March 2013

Email: I.greenwall@btconnect.com

BDA Seminar: To save or

to extract - how to solve

the treatment decision dilemma

Date: 8 March 2013

Venue: BDA, London

Email events@bda.org

Telephone: 02075634590

www.bda.org/seminars

British Dental Conference

\&t Exhibition 2013

Date: 25-27 April 2013

Venue: ExCel London

www.bda.org/conference

BDA Seminar: Contemporary management of restored teeth

Date: 24 May 2013

Venue: BDA, London

Email events@bda.org

Telephone: 02075634590

www.bda.org/seminars

\title{
MAPLE DENTAL CARE CROWNED PRACTICE OF THE YEAR
}

Maple Dental Care Ltd were awarded British Dental

Association (BDA) Good Practice

Scheme Practice of the Year

2012 at the seventh annual BDA

Honours and Awards Dinner held on 21 November at the Plaisterers' Hall, London.

Maple Dental Care Ltd is a mixed NHS and private dental practice founded in 1954 in Brooklands, Manchester and is also an approved NHS training practice for newly qualified dentists.

Numerous other awards were presented on the night including Fellowships for Lester Ellman, Mike Arthur, Raj Joshi and Richard Ward; and the Roll of distinction for Tony Reed, Philip Sutcliffe and Linda Wallace MBE. The $B D J$ s own Stephen Hancocks OBE provided characteristic witty repartee as Master of Ceremonies.

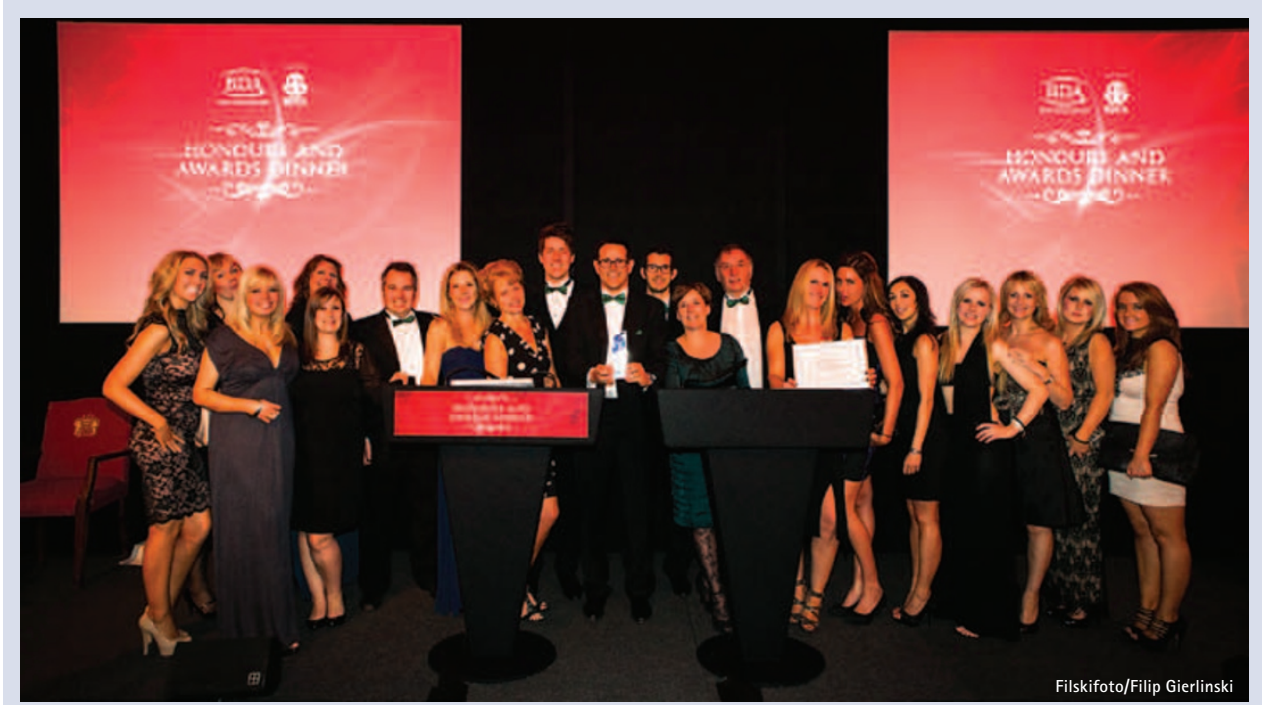

The Maple Dental Care dental team receiving their Good Practice award

\section{BISPHOSPHONATE-RELATED OSTEONECROSIS OF THE JAW IS RARE}

A two-year national study based on patient case records has concluded that incidence of bisphosphonate-related osteonecrosis of the jaw (BRONJ) can be considered as rare.

This study, a collaboration between the Faculty of General Dental Practice (UK) (FGDP [UK]) and the British Association of Oral and Maxillofacial Surgeons (BAOMS), was designed to capture all new referrals of patients with avascular necrosis of the jaw, including BRONJ, to oral and maxillofacial departments and dental hospitals in England, Wales, Scotland and Northern Ireland, from June 2009 to May 2011.

One of the two clinical leads for the study was Professor Simon Rogers for BAOMS, who commented: 'Although the data need to be interpreted with caution, the report would suggest that there are around 600 cases of BRONJ each year in the UK, and around 400 of these are related to oral bisphosphonates. Considering how commonly bisphosphonates are prescribed for conditions such as osteoporosis, these results should serve to reassure the public given the relative small number of cases of BRONJ each year. Further data and research is required.' The other clinical lead was Dr Nikolaus
Palmer for the FGDP(UK), while other stakeholders included the British Society of Oral Medicine, the British Association of Oral Surgeons and the Faculty of Dental Surgery of the Royal College of Surgeons of England.

BRONJ can develop as an adverse effect of taking bisphosphonate medication, used for the management of osteoporosis and in the treatment of some cancers. Up until now there have been no published studies providing a reliable estimate of the incidence of avascular necrosis, specifically BRONJ, in the general population. This study aimed to give a better understanding of the incidence, case management and risk factors of BRONJ in relation to outcome for patient care management.

The full report can be viewed at www.fgdp.org.uk/research/facultystudiesprojects.ashx. 